Article

\title{
Reaction Rate Study of the Photocatalytic Degradation of Dichloroacetic Acid in a Black Body Reactor
}

\author{
Lena Megatif ${ }^{1}$, Ralf Dillert ${ }^{1,2, *(1)}$ and Detlef W. Bahnemann ${ }^{1,2,3}$ (1) \\ 1 Institut für Technische Chemie, Gottfried Wilhelm Leibniz Universität Hannover, Callinstrasse 3, \\ 30167 Hannover, Germany \\ 2 Laboratorium für Nano- und Quantenengineering, Gottfried Wilhelm Leibniz Universität Hannover, \\ Schneiderberg 39, 30167 Hannover, Germany \\ 3 Laboratory "Photoactive Nanocomposite Materials", Saint-Petersburg State University, Ulyanovskaya str. 1, \\ Peterhof, 198504 Saint-Petersburg, Russia \\ * Correspondence: dillert@iftc.uni-hannover.de; Tel.: +49-511-762-16039
}

Received: 12 June 2019; Accepted: 19 July 2019; Published: 25 July 2019

check for updates

\begin{abstract}
The light-induced degradation of dichloroacetic acid in aqueous suspensions containing the $\mathrm{TiO}_{2}$ photocatalyst Hombikat UV 100 was investigated. The reactions were performed in a black body reactor in which the rate of conversion, defined as the time derivative of the extent of conversion, is not affected by the light scattering properties of the photocatalysts. At sufficiently high concentrations of both the probe compound and the photocatalyst the rate of conversion was found to be unswayed by the initial concentration of the probe compound, the mass concentration of the photocatalyst, and the suspension volume. Thus, the chosen experimental conditions enable the determination of the rate of conversion and the quantum yield of the light induced degradation of dichloroacetic acid in aqueous photocatalyst suspension with sufficiently good reproducibility. The experimental procedure employed here seems to be generally applicable to determine rates of conversion and quantum yields that possibly allow a comparison of the activities of photocatalysts in aqueous suspensions.
\end{abstract}

Keywords: black body photoreactor; dichloroacetic acid; heterogeneous photocatalysis; quantum yield; rate of conversion; titanium dioxide

\section{Introduction}

Heterogeneous photocatalysis in solid-liquid systems is considered as an effective method to harvest photons for the oxidative degradation of organic water pollutants, the generation of molecular hydrogen by water splitting or reforming of organic compounds, the fixation of carbon dioxide or molecular nitrogen, and the synthesis of organic compounds. Therefore, new photocatalysts and photocatalytically active composites are being synthesized and investigated with respect to possible applications in heterogeneous photocatalysis [1-8].

Technically applicable photocatalysts must meet a number of requirements. It is crucial that the photocatalytically active solid is stable under the conditions of the desired light-induced chemical reaction, and that it has a high photocatalytic activity. The latter condition inevitably requires the comparative assessment of the activities of semiconductors and composites intended as photocatalysts.

Several methods have been proposed for this comparative assessment of photocatalytic activities in suspensions. For details on the proposed methods, the curious reader is referred to the recently published papers of Kisch and Bahnemann [9], Qureshi and Takanabe [10], Hoque and Guzman [11], and the references given therein. Usually, the reaction rate at which a probe compound is photocatalytically converted, is used as the measure of the photocatalytic activity of the solid under consideration. The activities of different photocatalysts are then assessed by comparing the numerical values of the 
respective rates. Reaction rates are usually reported on a volume basis (converted amount of the probe compound per unit time and unit suspension volume), a mass basis (converted amount per unit time and unit mass of photocatalyst), or an area basis (converted amount per unit time and unit surface area of photocatalyst). A photocatalytic reaction, however, takes place only in the small volume inside the photoreactor that is located directly behind the light entrance. In this volume, the photon flux decreases as the distance from the entrance window increases. This, of course, is accompanied by a decrease in the reaction rate, which becomes zero in the more distant layers of the suspension, which are not penetrated by photons. A reported reaction rate is consequently always a volume averaged value. A prerequisite for the comparison of reaction rates is that the values were determined under identical reaction conditions [9]. Consequently, the comparison of published values is impeded due to the lack of detailed information on the geometry of the photoreactor, the size of the entrance window, and the characteristics of the irradiation conditions.

To avoid this draw-back, it has been proposed to calculate the ratio between the amounts of the probe compound reacted in a time interval and the photons impinging on the outer wall of the light entrance in this time interval. However, objections have been raised against this ratio, which is called the photonic efficiency (also known as quantum efficiency), as a measure of the photocatalytic activity of a material. In almost all published papers reporting comparative studies of photocatalysts in suspensions, experimental setups were used, in which the slurries are irradiated by an external light source through a window in the outer wall of the photoreactor. In such an arrangement of photoreactor and light source (positive irradiation geometry), a fraction of the photons entering the suspension is not absorbed, but back-scattered out of the slurry and the reactor [12-15]. This undesired loss of photons can vary between $13 \%$ and $76 \%$ of the incoming light [12]. The ratio between absorbed and out-scattered photons depends, inter alia, on the photocatalyst composition, its particle size, and its mass concentration [16-18]. A reaction rate determined with an experimental set-up having positive irradiation geometry and, consequently, the resulting photonic efficiency thus also reflects the optical properties of the suspension and is, therefore, not a measure of the intrinsic activity of the photocatalyst under consideration.

Recently, Emeline and co-authors have proposed a particular design of a reactor with negative irradiation geometry in which the light entrance is surrounded by the suspension in all three spatial directions (as far as technically feasible) [19]. The design of this photoreactor ensures that almost all out-scattered photons re-enter the suspension elsewhere. Provided that no photons are transmitted through the suspension, all the photons with appropriate energy to excite the photocatalyst are absorbed inside the suspension. Although the reactor filled with the suspension behaves like a black body only in a finite wavelength range, it was termed as a black body-like reactor by Emeline et al. [19].

Provided that the photocatalyst is the only light absorbing species and that the suspension is optically dense for photons having an energy greater than the bandgap energy of the photocatalyst (i.e., no photons are transmitted through the reactor), all the photons with appropriate energy emitted by the light source are absorbed by the photocatalyst. All photons emitted by the light source are therefore available to initiate a photocatalytic reaction. The rate of a photocatalytic reaction as a measure of the photocatalytic activity is thus diminished only by the recombination of the photogenerated charge carriers and is independent from the scattering properties of the photocatalyst. The amount of photons emitted by the light source and entering the black body-like photoreactor can easily be determined by chemical actinometry. When using a monochromatic light source, a quantum yield-as is usual for homogeneous photochemical reactions-can thus be calculated [19]. However, it must be emphasized that a quantum yield will only be meaningful if the photocatalyst is the only species that absorbs the photons entering the suspension. In order to determine the quantum yield of a light-induced reaction in a photocatalyst suspension, the probe compound must therefore be optically transparent. In addition, the photocatalytic conversion of the probe compound must not yield intermediates and products capable to absorb the incoming light. 
Dichloroacetic acid (DCA) is an organic compound that meets these requirements when irradiated with visible and UV(A) light. DCA presents some additional advantages for laboratory studies due to its low vapor pressure and high water solubility [20]. An additional advantageous reason to use DCA as the probe compound is given by the fact that the photocatalytic reaction according to

$$
\mathrm{CHCl}_{2} \mathrm{COO}^{-}+\mathrm{O}_{2} \rightarrow 2 \mathrm{CO}_{2}+\mathrm{H}^{+}+2 \mathrm{Cl}^{-}
$$

can be monitored not only by measuring the DCA concentration [20-24], but also by measuring the concentration of organic carbon (TOC) $[20,21,25]$, as well as the evolved amounts of $\mathrm{CO}_{2}$ [26], $\mathrm{Cl}^{-}[20,21,26,27]$, and $\mathrm{H}^{+}$(employing, e.g., a pH-stat technique [27-30]) to determine the photocatalytic reaction rate. However, for the direct comparison of the rates obtained by the measurements of these analytes, it is recommended that the rates of conversion as defined by the IUPAC are used [31]. The rate of conversion of a species $i$ is defined as the time derivative of the extent of reaction $\xi(\mathrm{i})$

$$
\frac{\mathrm{d} \xi(\mathrm{i})}{\mathrm{d} t}=\frac{1}{v(\mathrm{i})}\left(\frac{\mathrm{d} n(\mathrm{i})}{\mathrm{d} t}\right)=\frac{V}{v(\mathrm{i})}\left(\frac{\mathrm{d} C(\mathrm{i})}{\mathrm{d} t}\right)
$$

where $n(\mathrm{i})$ and $C(\mathrm{i})$ are the amount and the amount concentration (molarity), respectively, of this species at any time $t, v(\mathrm{i})$ is its stoichiometric coefficient, and $V$ is the volume of the suspension.

If Equation (1) is valid, then the equality $\mathrm{d} \xi(\mathrm{DCA}) / \mathrm{d} t=\mathrm{d} \xi\left(\mathrm{CO}_{2}\right) / \mathrm{d} t=\mathrm{d} \xi\left(\mathrm{Cl}^{-}\right) / \mathrm{d} t$ must be satisfied during the photocatalytic degradation of DCA. However, the evaluation of published data employing the rates of conversion suggests that the numerical values are slightly different for the different analytes $[20,21,26]$. Such differences in the rates of conversion would then have to be taken into account when comparing published data for one reactant but obtained with different analytes.

This article reports on the photocatalytic oxidation of dichloroacetic acid in acidic aqueous suspensions employing a black body-like reactor. The initial concentration of DCA, the mass concentration of the photocatalyst $\mathrm{TiO}_{2}$ Hombikat UV 100, the volume of the suspension, and the photon flux were varied. The experimental conditions were chosen such that the DCA concentration decreases linearly with the irradiation time, with the result that the kinetics of the photocatalytic degradation of DCA is approximated by a zero-order rate law. This work was performed to answer two scientific questions: (i) How reproducible are the results of photocatalytic degradation experiments performed in a black body photoreactor? (ii) Are the rates of conversion for the reactant and the reaction product (here DCA and $\mathrm{Cl}^{-}$) the same within the limits of experimental error? This paper thus complements our recent publications, in which we have used the black body photoreactor for the comparative assessment of heterogeneous photocatalysts and for the determination of the quantum yields of heterogeneous photocatalytic reactions [23,24].

\section{Results}

The light induced degradation of dichloroacetic acid (DCA) in the presence of Hombikat UV 100 as the photocatalyst was studied by varying the initial concentration of the probe compound $\left(2 \mathrm{mmol} \mathrm{L}^{-1} \leq C_{\mathrm{s}} \leq 20 \mathrm{mmol} \mathrm{L}^{-1}\right)$, the mass concentration of the photocatalyst $\left(1 \mathrm{~g} \mathrm{~L}^{-1} \leq \gamma \leq 10 \mathrm{~g} \mathrm{~L}^{-1}\right)$, the suspension volume $(80 \mathrm{~mL} \leq V \leq 900 \mathrm{~mL})$, and the photon flux into the suspension $(0.54 \mu \mathrm{mol}$ $\left.\min ^{-1} \leq \mathrm{d} n_{\mathrm{p}} / \mathrm{d} t \leq 10.7 \mu \mathrm{mol} \mathrm{min}^{-1}\right)$. The temperature, the concentration of dissolved oxygen, the $\mathrm{pH}$, and the ionic strength were kept almost constant. After adding the photocatalyst to the aqueous DCA solution and $\mathrm{pH}$ adjustment, the suspensions were stirred in the dark for two hours prior to irradiation. In all experimental runs the DCA concentration was found to decrease during this dark period, i.e., the DCA concentration $C_{0}$ at the time when the light source was switched on $(t=0)$ was always found to be lower than the DCA concentration $C_{s}$ of the stock solution. The monochromatic light was directed by means of a wave guide into the center of the suspension. The light inlet was thus surrounded by the suspension in all spatial directions. Therefore, it can be assumed that the condition for a blackbody reactor, i.e., all incident photons are absorbed in the suspension, is satisfied. 
In a first set of experimental runs, the impact of the amount concentration of DCA on the reaction rate was investigated. Therefore, the initial concentration of DCA was varied at a constant mass concentration of the photocatalyst $\left(\gamma=5 \mathrm{~g} \mathrm{~L}^{-1}\right)$, a constant photon flux $\left(\mathrm{d} n_{\mathrm{p}} / \mathrm{d} t=10.7 \mu \mathrm{mol} \mathrm{min}{ }^{-1}\right)$, and a constant suspension volume $(V=400 \mathrm{~mL})$. Figure $1 \mathrm{~A}$ illustrates the change of the DCA concentration as determined by HPIC during UV(A) irradiation for experimental runs with DCA concentrations $C_{\mathrm{s}}$ varying between $2 \mathrm{mmol} \mathrm{L}^{-1}$ and $20 \mathrm{mmol} \mathrm{L}^{-1}$. It becomes obvious from this figure, that the DCA concentration decreased linearly with time during UV(A) irradiation. The degradation rates defined as the time derivative of the amount concentration $(\mathrm{d} C / \mathrm{d} t)$ are directly obtained from the slope of the graphs. The numerical values of the thus calculated degradation rates are given in Figure 1B. The rates were found to be constant within the limits of experimental error $\left(\mathrm{dC} / \mathrm{d} t=4.79 \pm 0.56 \mu \mathrm{mol} \mathrm{L}^{-1} \mathrm{~min}^{-1}\right)$ and not affected by the initial concentration of DCA at the experimental conditions employed here. The rate of conversion was calculated inserting the reaction rate, the suspension volume $V$, and the stoichiometric coefficient $v(\mathrm{DCA})=1$ into Equation (2). A mean

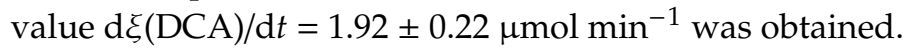
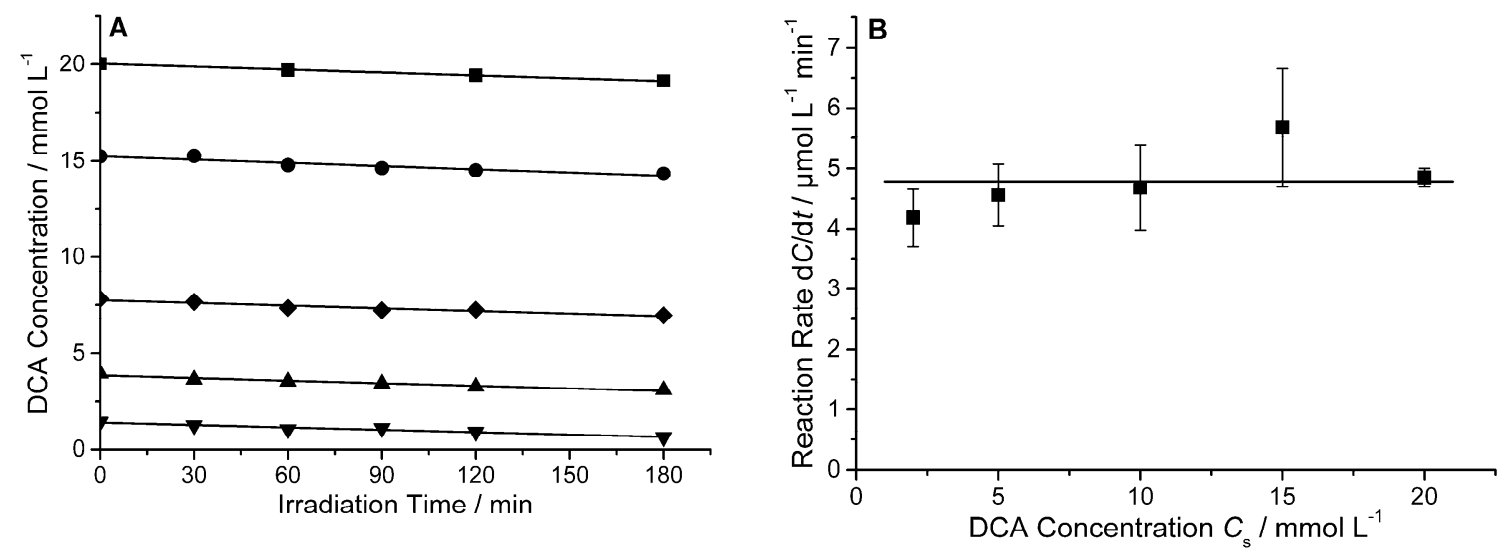

Figure 1. Photocatalytic degradation of dichloroacetic acid (DCA) varying the initial concentration: (A) Concentration vs. time profiles of suspensions with DCA concentrations of $20(\mathbf{\square}), 15(\bullet), 10(\bullet)$, $5(\mathbf{\Lambda})$, and $2 \mathrm{mmol} \mathrm{L}^{-1}(\mathbf{v}) ;(\mathbf{B})$ Reaction rates $\mathrm{d} C / \mathrm{d} t$ (calculated from the slopes of the plots in (A)) vs. the concentration of the stock solution $C_{\mathrm{s}}$. The line in (B) represents the average of the five data points. Experimental conditions: Hombikat UV 100, $\gamma=5 \mathrm{~g} \mathrm{~L}^{-1}, V=400 \mathrm{~mL}$, photon flux $=10.7 \mu \mathrm{mol} \mathrm{min}^{-1}$, $\mathrm{pH}$ 3, $10 \mathrm{mmol} \mathrm{L}^{-1} \mathrm{KNO}_{3}$, air saturated, ambient temperature.

In a second set of experimental runs the impact of the mass concentration of the photocatalyst on the DCA degradation rate was investigated. The initial concentration of DCA $\left(C_{\mathrm{s}}=10 \mathrm{mmol} \mathrm{L}^{-1}\right)$, the photon flux $\left(\mathrm{d} n_{\mathrm{p}} / \mathrm{d} t=10.7 \mu \mathrm{mol} \mathrm{\textrm {min } ^ { - 1 }}\right)$, and the suspension volume $(V=400 \mathrm{~mL})$ were kept constant during these experimental runs. The measured DCA concentrations are plotted versus the irradiation time in Figure 2A. Again, linear concentration-time plots were obtained enabling the determination of the DCA degradation rates from the slopes of these plots. The degradation rates were found to be constant $\left(\mathrm{d} C / \mathrm{d} t=5.54 \pm 0.43 \mu \mathrm{mol} \mathrm{L}{ }^{-1} \mathrm{~min}^{-1}\right)$ and not affected by the mass concentration $\gamma$ of the photocatalyst Hombikat UV 100 (Figure 2B). With this reaction rate, a mean rate of conversion $\mathrm{d} \xi(\mathrm{DCA}) / \mathrm{d} t=2.22 \pm 0.17 \mu \mathrm{mol} \mathrm{min}^{-1}$ is calculated employing Equation (2).

In a third set of experimental runs, the suspension volume was varied at constant initial concentration of DCA $\left(C_{\mathrm{s}}=10 \mathrm{mmol} \mathrm{L}^{-1}\right)$, photon flux $\left(\mathrm{d} n_{\mathrm{p}} / \mathrm{d} t=10.7 \mu \mathrm{mol} \mathrm{min}{ }^{-1}\right)$, and mass concentration of the photocatalyst $\left(\gamma=5 \mathrm{~g} \mathrm{~L}^{-1}\right)$. Again, linear concentration-time plots were obtained (Figure 3A). However, when the degradation rates determined from the slopes of these concentration-time plots are plotted versus the suspension volume, a non-linear decrease is observed (Figure 3B) as expected for the photocatalytic degradation of a probe compound in suspension. The reaction rates have been fitted using a regression curve $\mathrm{d} C / \mathrm{d} t=k / V$ with $k=1.82 \pm 0.04 \mu \mathrm{mol} \mathrm{min}{ }^{-1}$. Since the stoichiometric coefficient of DCA is unity, this value $k$ corresponds directly to the rate of 
conversion $\mathrm{d} \xi(\mathrm{DCA}) / \mathrm{d} t$ defined by Equation (2). The good agreement between the experimental and the fitted values clearly indicate the independence of the rate of conversion from the suspension volume within the limits of experimental error. This also clearly demonstrates that the experimental set-up employed here behaves like a black body reactor: with a given photocatalyst and under the condition of (apparent) zero-order kinetics with respect to the organic solute, constant photon fluxes result in constant rates of conversion!
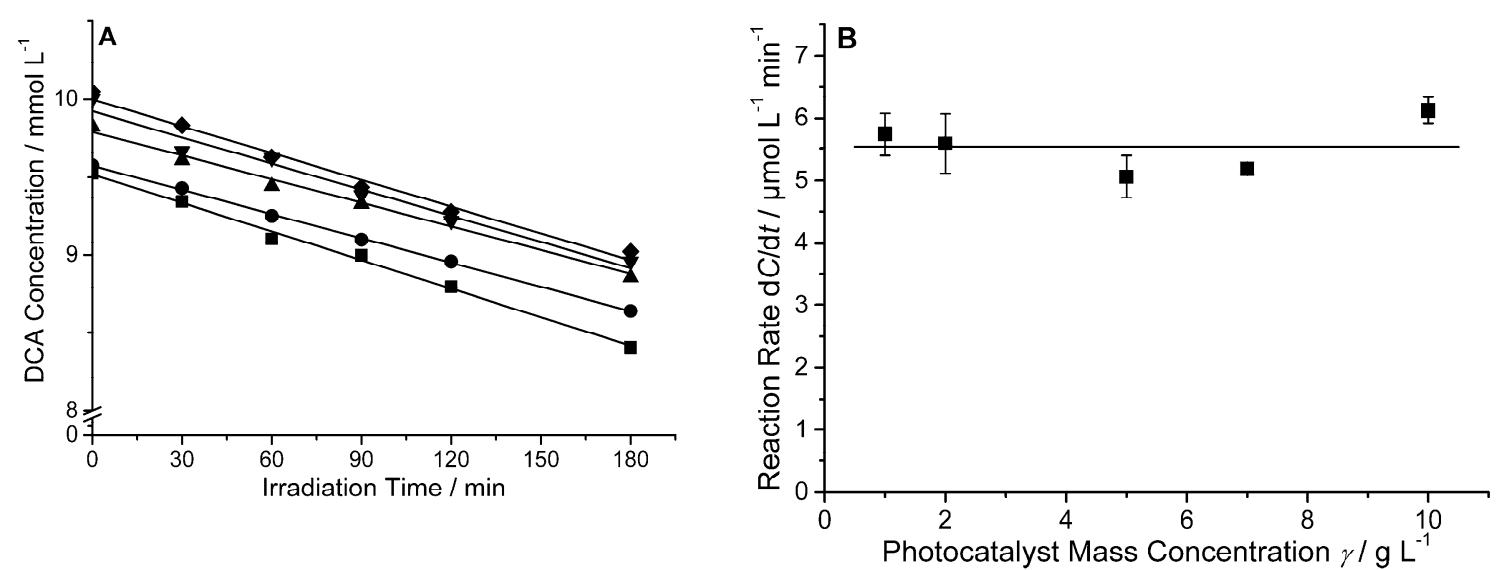

Figure 2. Photocatalytic degradation of dichloroacetic acid (DCA) varying the mass concentration of the photocatalyst Hombikat UV 100: (A) Concentration vs. time profiles of suspensions with catalyst concentrations of $10(\boldsymbol{\bullet}), 7(\bullet), 5(\mathbf{\Delta}), 2(\mathbf{v})$, and $1 \mathrm{~g} \mathrm{~L}^{-1}(\bullet) ;(\mathbf{B})$ Reaction rates $\mathrm{d} C / \mathrm{d} t$ (calculated from the slopes of the plots in (A)) vs. mass concentration $\gamma$. The line in (B) represents the average of the five data points. Experimental conditions: $C_{\mathrm{s}}=10 \mathrm{mmol} \mathrm{L}^{-1}, V=400 \mathrm{~mL}$, photon flux $=10.7 \mu \mathrm{mol} \mathrm{min}^{-1}$, $\mathrm{pH}$ 3, $10 \mathrm{mmol} \mathrm{L}^{-1} \mathrm{KNO}_{3}$, air saturated, ambient temperature.
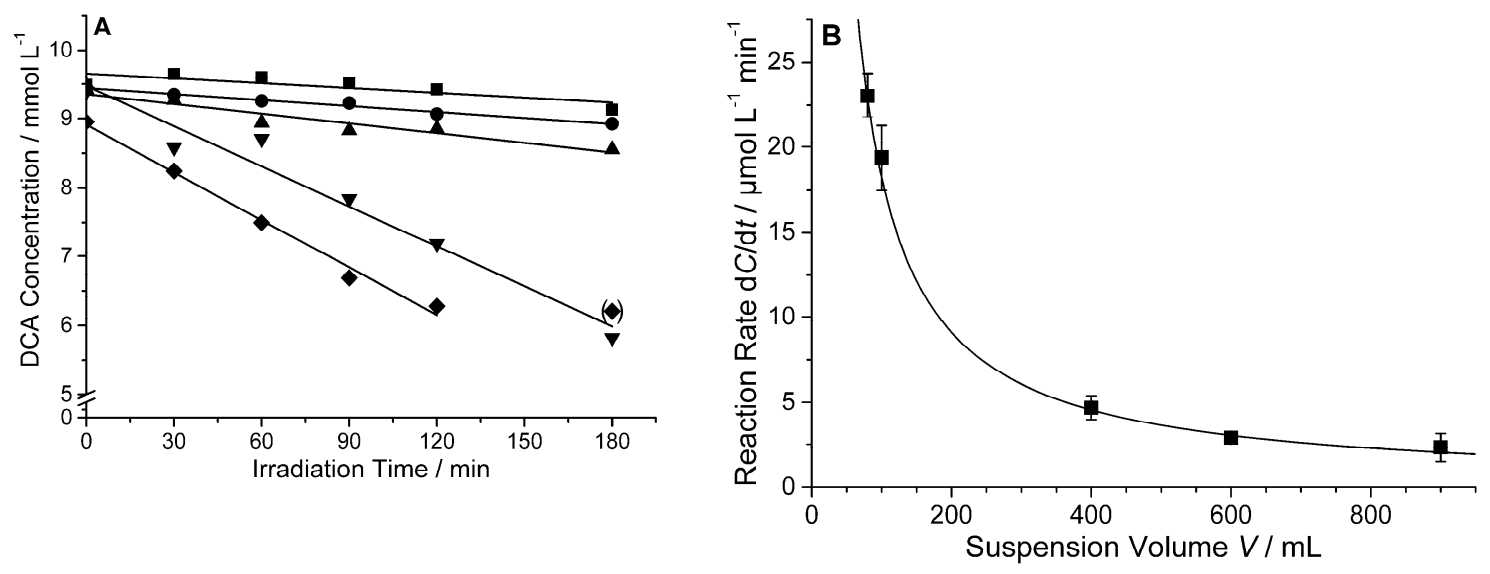

Figure 3. Photocatalytic degradation of dichloroacetic acid (DCA) varying the suspension volume: (A) Concentration vs. time profiles obtained with $900(\boldsymbol{\square}), 600(\bullet), 400(\mathbf{\Lambda}), 100(\mathbf{v})$, and $80 \mathrm{~mL}$ ( $)$ suspension; (B) Reaction rates $\mathrm{d} C / \mathrm{d} t$ (calculated from the slopes of the plots in (A)) vs. the suspension volume $V$. The line in (B) was calculated with $\mathrm{d} C / \mathrm{d} t=k / V$ and $k=1.82 \mu \mathrm{mol} \mathrm{min}^{-1}$. Experimental

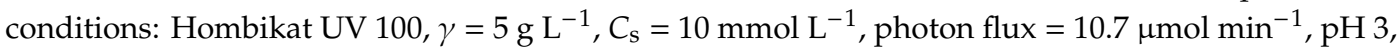
$10 \mathrm{mmol} \mathrm{L}{ }^{-1} \mathrm{KNO}_{3}$, air saturated, ambient temperature.

Finally, the impact of the photon flux $\left(0.54 \mu \mathrm{mol} \mathrm{min}^{-1} \leq \mathrm{d} n_{\mathrm{p}} / \mathrm{d} t \leq 10.7 \mu \mathrm{mol} \mathrm{min}^{-1}\right)$ on the reaction rate was investigated. The initial concentration of DCA $\left(C_{\mathrm{s}}=10 \mathrm{mmol} \mathrm{L}^{-1}\right)$, the mass concentration of the photocatalyst $\left(\gamma=5 \mathrm{~g} \mathrm{~L}^{-1}\right)$, and the suspension volume $(400 \mathrm{~mL})$ were kept constant. Figure $4 \mathrm{~A}$ depicts the measured DCA concentrations versus the irradiation time for five selected experimental runs performed with different photon fluxes. Linear concentration-time plots were obtained with all photon fluxes in the range mentioned above, thus indicating that the photon flux is not affecting 
the kinetics of the DCA degradation reaction. The rates calculated from the slopes of these plots are presented in Figure 4B. A non-linear relation between the calculated degradation rates and the photon fluxes becomes obvious.
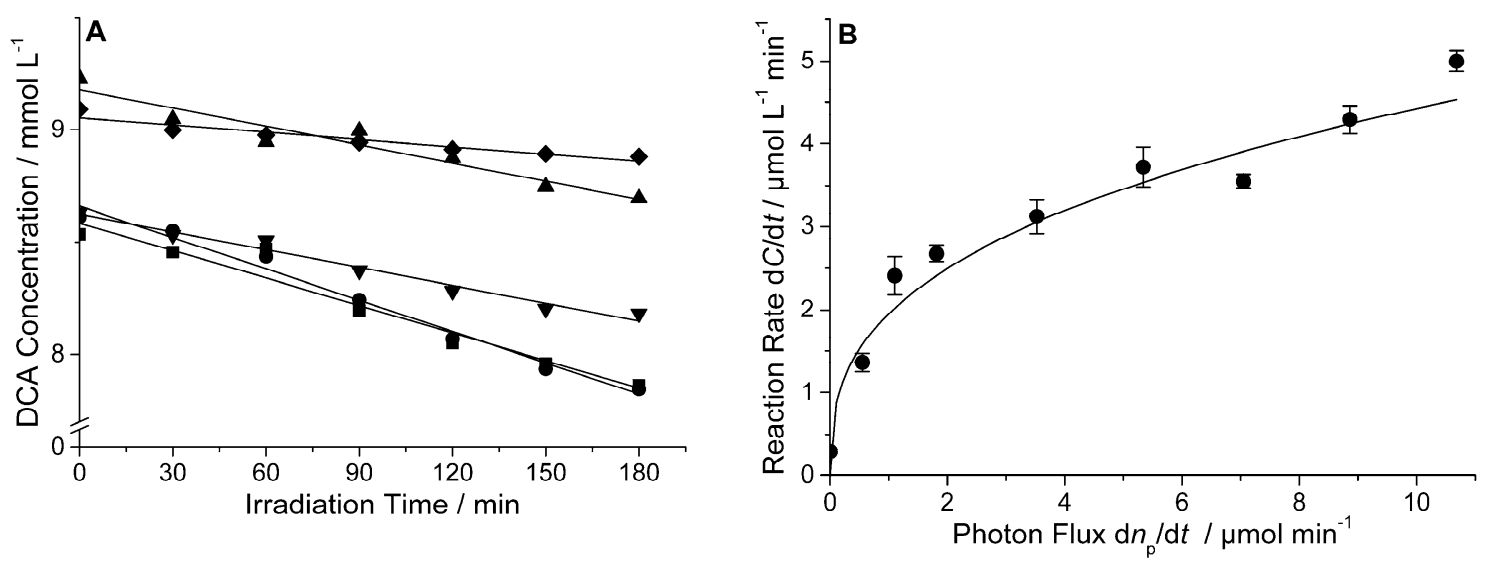

Figure 4. Photocatalytic degradation of dichloroacetic acid (DCA) at varying photon fluxes: (A) Concentration vs. time profiles obtained with photon fluxes of $0.54(\boldsymbol{\bullet}), 1.80(\boldsymbol{\nabla}), 3.54(\mathbf{\Lambda})$, $5.34(\bullet)$, and $8.88 \mu \mathrm{mol} \mathrm{min}^{-1}(\mathbf{\square})$; (B) Reaction rates $\mathrm{d} C / \mathrm{d} t$ (calculated from the slopes of the plots in $(\mathbf{A}))$ vs. the photon flux. The line in $(\mathbf{B})$ were calculated assuming an exponential dependence of the reaction rate on the photon flux $\left(\mathrm{d} C / \mathrm{d} t \approx\left[\mathrm{d} n_{\mathrm{p}} / \mathrm{d} t\right]^{\alpha}\right.$ with $\left.\alpha=0.35\right)$. Experimental conditions: Hombikat UV 100, $\gamma=5 \mathrm{~g} \mathrm{~L}^{-1}, \mathrm{C}_{\mathrm{s}}=10 \mathrm{mmol} \mathrm{L}^{-1}, V=400 \mathrm{~mL}, \mathrm{pH} 3,10 \mathrm{mmol} \mathrm{L}{ }^{-1} \mathrm{KNO}_{3}$, air saturated, ambient temperature.

\section{Discussion}

In all experimental runs performed here, a decrease of the DCA concentration accompanied by a simultaneous increase of the $\mathrm{Cl}^{-}$concentration was observed during UV(A) irradiation of aqueous DCA-TiO ${ }_{2}$ slurries. No significant change in the concentrations was observed when irradiating homogeneous DCA solutions with $\mathrm{UV}(\mathrm{A})$ light. Stirring of DCA-containing $\mathrm{TiO}_{2}$ suspensions in the dark resulted in an initial decrease of the DCA concentration. However, no increase of the concentration of $\mathrm{Cl}^{-}$was observed. Therefore, the observed changes in the DCA and $\mathrm{Cl}^{-}$concentrations in UV(A) irradiated Hombikat UV 100 suspensions can only be attributed to a photocatalytic degradation of the organic solute. The main reaction steps of the photocatalytic DCA degradation at the acidic $\mathrm{pH}$ of the suspension employed here ( $\mathrm{pH} 3$ ) are given by the Equations (3) to (9) (adapted from [20,21]):

$$
\begin{aligned}
& \mathrm{TiO}_{2}+\mathrm{O}_{2} \rightleftharpoons \mathrm{TiO}_{2}-\mathrm{O}_{2} \text { ads } \\
& \mathrm{TiO}_{2}+\mathrm{CHCl}_{2} \mathrm{COO}^{-} \rightleftharpoons \mathrm{TiO}_{2}-\mathrm{CHCl}_{2} \mathrm{COO}^{-} \text {ads } \\
& \mathrm{TiO}_{2}-\mathrm{CHCl}_{2} \mathrm{COO}^{-} \text {ads }+\mathrm{h}^{+} \rightarrow \mathrm{TiO}_{2}-\mathrm{CHCl}_{2} \mathrm{COO}^{\bullet} \text { ads } \\
& \mathrm{CHCl}_{2} \mathrm{COO}^{\bullet} \text { ads } \rightarrow{ }^{\bullet} \mathrm{CHCl}_{2} \text { ads }+\mathrm{CO}_{2} \\
& \mathrm{O}_{2 \text { ads }}+{ }^{\bullet} \mathrm{CHCl}_{2 \text { ads }} \rightarrow{ }^{\bullet} \mathrm{OOCHCl}_{2} \text { ads } \\
& 2 \cdot \mathrm{OOCHCl}_{2} \text { ads } \rightarrow 2 \mathrm{COCl}_{2}+\mathrm{H}_{2} \mathrm{O}_{2} \\
& \mathrm{COCl}_{2}+\mathrm{H}_{2} \mathrm{O} \rightarrow \mathrm{CO}_{2}+2 \mathrm{H}^{+}+2 \mathrm{Cl}^{-}
\end{aligned}
$$

At $\mathrm{pH} 3, \mathrm{DCA}$ is mainly dissociated in its constituting ions $\left(\mathrm{pK}_{\mathrm{a}}(\mathrm{DCA})=1.06\right.$ [32]) resulting in the adsorption of negatively charged dichloroacetate ions at the positively charged $\mathrm{TiO}_{2}$ surface (Equation (4)). The reaction pathway given by the Equations (3) to (9) takes into account that the oxidation of adsorbed dichloroacetate is initiated by an interfacial electron transfer from the adsorbate to a hole that is produced upon light excitation of a photocatalyst particle. The mechanism thus considers 
that, in acidic $\mathrm{TiO}_{2}$ suspensions, direct attack of the organic adsorbate by holes is significantly more important than oxidation by $\mathrm{OH}$ radicals as clearly demonstrated in previous publications reporting the photocatalytic degradation of carboxylic acids [20,21,33-43]. The dichloroacetoxy radical formed by direct hole oxidation of adsorbed DCA (Equation (5)) decarboxylates yielding a carbon-centered radical (photo-Kolbe reaction, Equation (6)) which reacts with molecular oxygen in a subsequent reaction step (Equation (7)). Two of the intermediate radicals react in a bimolecular reaction yielding hydrogen peroxide and phosgene (Equation (8)) which is immediately hydrolyzed into $\mathrm{CO}_{2}$ and $\mathrm{Cl}^{-}$ (Equation (9)). According to this reaction mechanism the absorption of one photon by a photocatalyst particle is required to initiate the complete mineralization of one DCA yielding $\mathrm{CO}_{2}, \mathrm{H}^{+}$, and $\mathrm{Cl}^{-}$. If this mechanistic scheme is valid, then $\mathrm{d} \xi(\mathrm{DCA}) / \mathrm{d} t=\mathrm{d} \xi\left(\mathrm{Cl}^{-}\right) / \mathrm{d} t$ must hold.

As discussed in the Introduction, the reaction rate $\mathrm{d} C / \mathrm{d} t$ of a photocatalytic reaction in suspension is a volume-averaged value calculated by integration of the local volumetric reaction rate $r_{x}$ over the entire suspension volume $V$

$$
\frac{\mathrm{d} C}{\mathrm{~d} t}=\langle r\rangle=\frac{1}{V} \int_{V} r_{x} \mathrm{~d} V .
$$

Consequently, the rates reported in the Figures $1 \mathrm{~B}, 2 \mathrm{~B}, 3 \mathrm{~B}$, and $4 \mathrm{~B}$ are volume-averaged values. The absorbed photons result in the formation of electron-hole pairs. A fraction of the formed electrons and holes recombine in a fast process. However, the remaining holes react with adsorbed dichloroacetate in a single electron transfer reaction according to Equation (5). The following equation applies for a black body photoreactor

$$
\frac{\mathrm{d} n_{\mathrm{p}, \mathrm{em}}}{\mathrm{d} t} \cong \frac{\mathrm{d} n_{\mathrm{p}, \mathrm{ads}}}{\mathrm{d} t}=\Phi^{-1}\left(\frac{\mathrm{d} \xi(\mathrm{DCA})}{\mathrm{d} t}\right)
$$

The parameter $\Phi=\mathrm{d} \xi(\mathrm{DCA}) / \mathrm{d} n_{\mathrm{p} \text {,abs }}$ corresponds to the volume averaged quantum yield of the photocatalytic degradation reaction under consideration [31].

In Figure 5, the rates of conversion $\mathrm{d} \xi(\mathrm{DCA}) / \mathrm{d} t$ for all experimental runs performed at a photon flux of $10.7 \mu \mathrm{mol} \mathrm{min}{ }^{-1}$ are plotted versus the DCA concentration $C_{\mathrm{s}}$, the mass concentration $\gamma$ of the photocatalyst and the suspension volume $V$. The average rate of DCA conversion was calculated as $\mathrm{d} \xi(\mathrm{DCA}) / \mathrm{d} t=2.02 \pm 0.24 \mu \mathrm{mol} \mathrm{min}{ }^{-1}(N=13)$. With this average rate of conversion and the photon flux of $10.7 \mu \mathrm{mol} \mathrm{min}{ }^{-1}$ emitted by the light source and determined by actinometry, the average quantum yield $\Phi$ of the photocatalytic DCA oxidation in the presence of Hombikat UV 100 was calculated to be $0.189 \pm 0.023$. For the purpose of comparison, the rates of conversion of $\mathrm{Cl}^{-}$are included in Figure 5 . The average rate of conversion was calculated to be $\mathrm{d} \xi\left(\mathrm{Cl}^{-}\right) / \mathrm{d} t=1.64 \pm 0.48 \mu \mathrm{mol} \mathrm{min}{ }^{-1}(N=13)$ which corresponds to an average quantum yield $\Phi=0.153 \pm 0.046$ for the photocatalytic DCA oxidation in acidic suspension containing Hombikat UV 100.

It becomes obvious from the data presented in Figure 5 that chloride is released slower than DCA is photocatalytically oxidized. The rate $\mathrm{d} \xi\left(\mathrm{Cl}^{-}\right) / \mathrm{d} t$ was found to be almost $20 \%$ lower than $\mathrm{d} \xi(\mathrm{DCA}) / \mathrm{d} t$. Obviously, the relation $\mathrm{d} \xi(\mathrm{DCA}) / \mathrm{d} t=\mathrm{d} \xi\left(\mathrm{Cl}^{-}\right) / \mathrm{d} t$, whose validity is mandatory if the DCA degradation follows the reaction path proposed above (Equation (3) - (9)), does not hold.

Chloride is known to adsorb on a $\mathrm{TiO}_{2}$ surface at acidic $\mathrm{pH}[28,44]$. A Langmuir adsorption constant of $0.69 \mathrm{~L} \mathrm{mmol}^{-1}$ was reported for the adsorption of $\mathrm{Cl}^{-}$on a Degussa P25 surface at $\mathrm{pH} 3$ [44]. Certainly, the adsorbed fraction of the photocatalytically generated $\mathrm{Cl}^{-}$is not available for the quantification by HPIC. Losses due to the evolution of molecular chlorine, which might be formed via hole oxidation of adsorbed $\mathrm{Cl}^{-}$and subsequent dimerization of two $\mathrm{Cl}^{\bullet}$, seems to be unlikely [44]. However, the formation of chloro-organic intermediates cannot be excluded. One possible reaction is the formation of tetrachloroethane by dimerization of two dichloromethyl radicals. Small amounts of tetrachloroethane were detected during the light-induced oxidation of dichloromethane in the presence of chlorocuprate ions [45], and in $\mathrm{O}_{2}$-free suspensions of $\mathrm{TiO}_{2}$ [46]. The analogous formation of ethane by dimerization of two methyl radicals was demonstrated to occur during the photocatalytic reaction of acetic acid in $\mathrm{O}_{2}$-free $[42,43,47,48]$ and in $\mathrm{O}_{2}$-containing $\mathrm{TiO}_{2}$ suspensions [48]. Possibly, reactions of ${ }^{\bullet} \mathrm{CHClCOO}^{-}$and ${ }^{\bullet} \mathrm{CCl}_{2} \mathrm{COO}^{-}$, whose intermediary formation and subsequent reactions 
to chloro-organic compounds has been discussed [49], must also be considered. Chemseddine and Boehm, who have investigated the photocatalytic DCA degradation in aqueous slurries of Degussa P25 $\mathrm{TiO}_{2}$, reported a rate of $\mathrm{CO}_{2}$ evolution significantly lower than the rate of $\mathrm{Cl}^{-}$formation. They emphasized, however, that almost all the chlorine bound in the reactant was released as chloride [26]. Asmus and co-workers observed the formation of small amounts of oxalic acid during irradiation of DCA in the presence of Degussa [50]. On the other hand, Ballari and co-authors, who have investigated the DCA degradation in the presence of an anatase $\mathrm{TiO}_{2}$, reported that 2 moles of $\mathrm{Cl}^{-}$are generated from 1 mole of degraded DCA, and that the chromatographically determined DCA concentrations were almost equal to the concentrations calculated from corresponding TOC measurements. They concluded that no stable organic intermediates are formed during the photocatalytic degradation of DCA [20]. Zalazar et al. reported small differences between the measured concentrations of organic carbon (TOC) and $\mathrm{Cl}^{-}$and the values expected from the measured DCA concentrations in the initial phase of the experimental runs. However, they claimed that a statistical test does not indicate these deviations are significant [21]. The preceding discussion suggests that the observed low rates of conversion of $\mathrm{Cl}^{-}$compared to the rates of conversion of DCA are most likely caused by losses due to the adsorption of $\mathrm{Cl}^{-}$on the photocatalyst surface. However, this should not preclude the possible formation of organochlorine compounds.
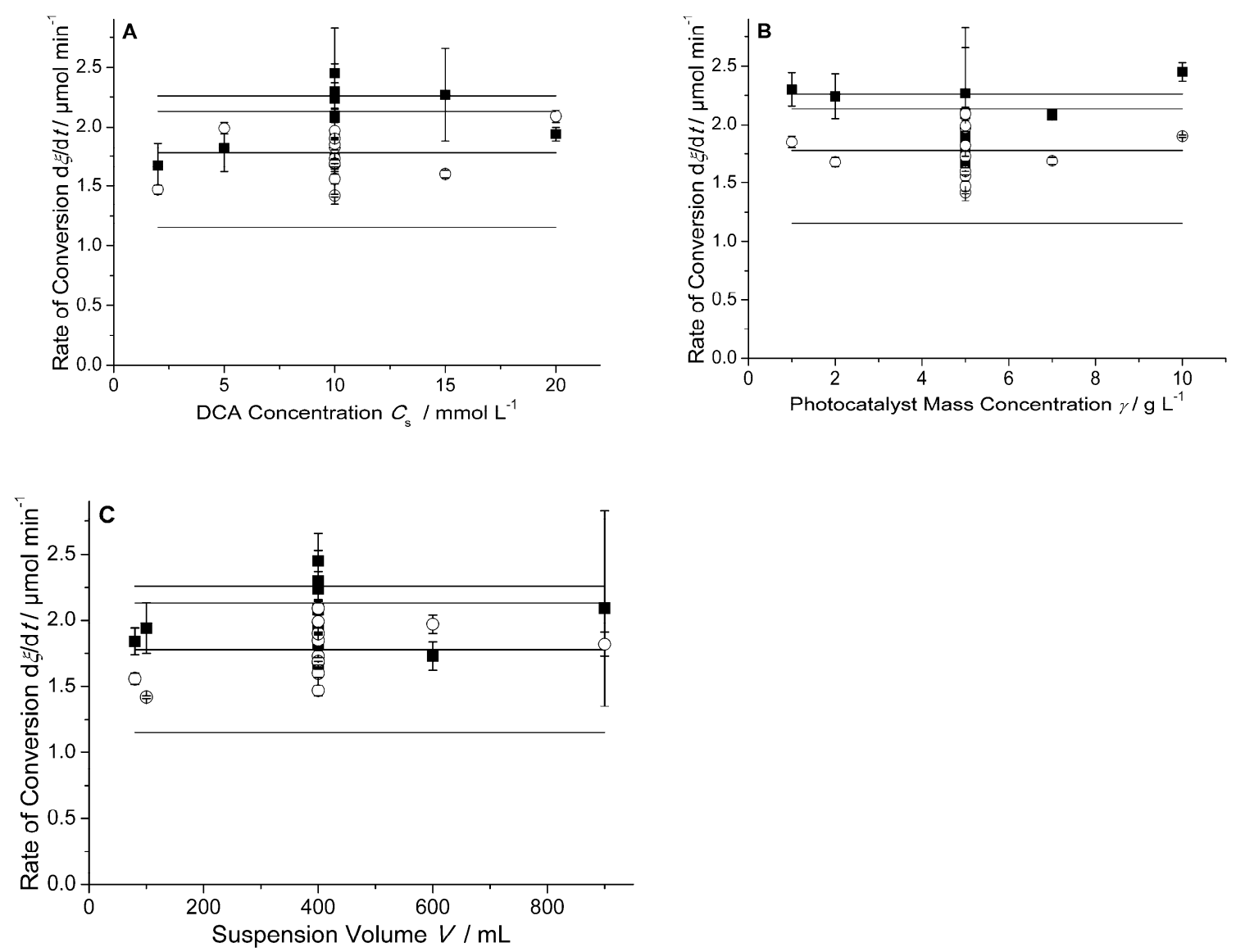

Figure 5. Rates of conversion $d \xi(D C A) / d t$ and $d \xi\left(C^{-}\right) / d t$ vs. (A) the DCA concentration $C_{\mathrm{s}}$, (B) the photocatalyst mass concentration $\gamma$, and (C) the suspension volume $V$. The lines represent the limits of

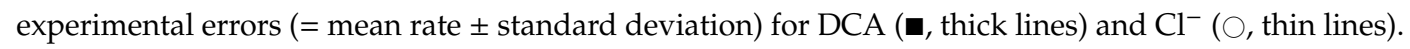

The rates of conversion $\mathrm{d} \xi(\mathrm{DCA}) / \mathrm{d} t$ and $\mathrm{d} \xi\left(\mathrm{Cl}^{-}\right) / \mathrm{d} t$ were found to be constant within the limits of experimental error and not affected by the initial concentration of the probe compound dichloroacetic acid, $C_{s}$, the mass concentration of the photocatalyst Hombikat UV 100, $\gamma$, and the suspension volume $V$, when $C_{\mathrm{s}}$ and $\gamma$ are larger than $2 \mathrm{mmol} \mathrm{L}^{-1}$ and $1 \mathrm{~g} \mathrm{~L}^{-1}$, respectively. The deviations from the 
average values of $d \xi(\mathrm{DCA}) / \mathrm{d} t$ and $\mathrm{d} \xi\left(\mathrm{Cl}^{-}\right) / \mathrm{d} t$ were found to be about $12 \%$ and $30 \%$, respectively. The observed variance is possibly due to the inhomogeneity of the commercial Hombikat UV 100, as had already been reported for Degussa P25 (now Aeroxide $\mathrm{TiO}_{2}$ P25, Evonik Industries AG, Essen, Germany) [51]. It should be noted, however, that the reproducibility found here for the rate of DCA conversion is within the usual range in photocatalytic experiments $[52,53]$. The larger experimental error in the determination of $\mathrm{d} \xi\left(\mathrm{Cl}^{-}\right) / \mathrm{d} t$ is attributed to the significantly lower concentrations of chloride formed during the photocatalytic degradation of DCA. Employing a black body photoreactor, rates of conversion can thus be determined with sufficiently good reproducibility.

The kinetics of light-induced reactions of organic compounds in photocatalyst suspensions are usually analyzed by Langmuir-Hinshelwood-type rate laws [53-63], which can all be written as

$$
\frac{\mathrm{d} C}{\mathrm{~d} t}=k_{1} \frac{k_{2} C}{k_{2} C+k_{3}} .
$$

Depending on the underlying mechanistic assumptions, the physical meaning of the kinetic parameters $k_{1}, k_{2}$, and $k_{3}$ are different in the different Langmuir-Hinshelwood-type rate laws [53-63]. It is well known, that the macroscopic reaction rate $\mathrm{d} C / \mathrm{d} t$ depends not only on the substrate concentration $C$ but also on the concentration of the photocatalyst $\gamma$ and the photon flux density $I_{0}$. The rate law given by Equation (12) explicitly describes only the correlation between the reaction rate and the substrate concentration. The dependence of the reaction rate on the other two mentioned variables is implicitly included in the kinetic parameters $k_{1}$ and $k_{3}$, which thus do not represent constants but functions of these variables. In an early work, it was deduced from mechanistic considerations that $k_{1}=k_{1}^{\prime} I_{0}^{\alpha}$, where the exponent $\alpha$ is 1 at low light intensities and 0.5 at high light intensities [54]. It has later been experimentally observed that in many cases $\mathrm{d} C / \mathrm{d} t$ is proportional to $I_{0}^{\alpha}$ with $0 \leq \alpha \leq 1$ [64]. This resulted in rate laws in which $k_{1}$ as well as $k_{3}$ are depending on $I_{0}[55,56,58,59,64]$. The concentration of the photocatalyst is at least included in $k_{1}$, which comprises the maximum concentration of available adsorption sites, which naturally depends on the photocatalyst concentration. However, the impact of the photocatalyst concentration on the rate of a photocatalytic reaction is usually low over a wide concentration range [12]. Other physico-chemical parameters such as temperature, ionic strength, oxygen concentration, and $\mathrm{pH}$, being known to affect the reaction rate, are assumed to be constant during the entire photocatalytic reaction, and are therefore usually not included in the kinetic expression.

During the derivation of most of the Langmuir-Hinshelwood-type rate laws used to interpret experimental data from photocatalytic degradation experiments it was ignored that the observed macroscopic reaction rate is a volume-averaged quantity. A macroscopic rate law for a photocatalytic reaction must however result from the integration of the local volumetric reaction rates over the entire suspension volume (Equation (10)). This approach was very recently used by Bloh and co-authors, resulting in a rate law which describes the impact of the concentration of the reactant $C$, the mass concentration of the heterogeneous photocatalyst $\gamma$, and the photon flux density $I_{0}$ on the observable macroscopic reaction rate $\mathrm{d} C / \mathrm{d} t[62,63]$. As this rate law was used to analyze the kinetic data presented in the Figure 1B, Figure 2B, and Figure $4 B$, the essential steps of the derivation are presented here to elucidate the restricting assumptions and simplifications.

Bloh assumed a bimolecular reaction between photo-generated reactive sites on the surface of the photocatalyst and the reactant. Essential in his approach is the ascertainment that only a limited number of sites on the photocatalyst surface are capable of forming these reactive surface sites. For the concentration of the reactive surface sites $C_{\mathrm{rs}}$ in a small volume within the suspension, he assumed a steady-state of formation, decay (recombination), and reaction with the reactant [63]

$$
\begin{aligned}
& \frac{\mathrm{d} C_{\mathrm{rs}}}{\mathrm{d} t}=0=r_{\text {formation }}-r_{\text {decay }}-r_{\text {reaction }} \\
& =\eta r_{\mathrm{p}, x} \frac{C_{\mathrm{rs}, 0}-C_{\mathrm{rs}}}{C_{\mathrm{rs}, 0}}-k_{\mathrm{d}} \frac{C_{\mathrm{rs}}}{C_{\mathrm{rs}, 0}}-k C_{\mathrm{rs}} C_{\mathrm{R}} .
\end{aligned}
$$


In this equation, $r_{\mathrm{p}, x}$ and $\eta$ are the local volumetric rate of photon absorption and the efficiency of the conversion of photons yielding reactive surface sites, respectively. The maximum concentration of reactive surface sites, the concentration of generated surface sites, and the concentration of the reactant are indicated as $C_{\mathrm{rs}, 0}, C_{\mathrm{rs}}$, and $C_{\mathrm{R}}$, respectively. The symbols $k_{\mathrm{d}}$ and $k$ represent the rate constants of the recombination and the interfacial charge transfer reaction. Employing this approach, the local rate $r_{x}$ of the considered photocatalytic reaction is given by

$$
r_{x}=\frac{\eta r_{\mathrm{p}, x} k C_{\mathrm{rs}, 0} C_{\mathrm{R}}}{\eta r_{\mathrm{p}, x}+k_{\mathrm{d}}+k C_{\mathrm{rs}, 0} C_{\mathrm{R}}} .
$$

For the derivation of the local rate of photon absorption, Bloh neglected scattering effects by the photocatalyst particles and assumed that the photon absorption is correctly described by the Lambert-Beer law [63]. This approach results in

$$
r_{\mathrm{p}, x}=\epsilon \gamma I_{0} \mathrm{e}^{-\epsilon \gamma d}
$$

Insertion of this expression for the local volumetric rate of photon absorption into Equation (14) yields the local reaction rate

$$
r_{x}=\frac{\epsilon \gamma \eta I_{0} \mathrm{e}^{-\epsilon \gamma d} k C_{\mathrm{rs}, 0} C_{\mathrm{R}}}{\epsilon \gamma \eta I_{0} \mathrm{e}^{-\epsilon \gamma d}+k_{\mathrm{d}}+k C_{\mathrm{rs}, 0} C_{\mathrm{R}}},
$$

and, after integration over the whole suspension volume, the macroscopic rate law of the photocatalytic conversion of the reactant

$$
\frac{\mathrm{d} C}{\mathrm{~d} t}=k C_{\mathrm{rs}, 0} C_{\mathrm{R}}+\frac{k C_{\mathrm{rs}, 0} C_{\mathrm{R}}}{\epsilon \gamma d} \times \ln \frac{\epsilon \gamma \eta I_{0}+k_{\mathrm{d}}+k C_{0} C_{\mathrm{R}}}{\epsilon \gamma \eta I_{0}+\left(k_{\mathrm{d}}+k C_{\mathrm{rs}, 0} C_{\mathrm{R}}\right) \mathrm{e}^{\epsilon \gamma d}} .
$$

This rate law simplifies for suspensions of high optical density, where $\mathrm{e}^{\epsilon \gamma d} \gg \frac{\epsilon \gamma \eta I_{0}}{k_{\mathrm{d}}+k C_{\mathrm{rs}, 0} C_{\mathrm{R}}}$ holds, into

$$
\frac{\mathrm{d} C}{\mathrm{~d} t}=\frac{k C_{\mathrm{rs}, 0} C_{\mathrm{R}}}{\epsilon \gamma d} \times \ln \left(\frac{\epsilon \gamma \eta I_{0}}{k_{\mathrm{d}}+k C_{\mathrm{rs}, 0} C_{\mathrm{R}}}+1\right)
$$

It should be noted that this derivation implicitly includes some additional assumptions. Thus, it is assumed that both the reactant and the photocatalyst are uniformly distributed throughout the suspension volume so no concentration gradients become operative. Moreover, the derivation assumes that the photocatalyst is the only light-absorbing species and that the conversion of monochromatic light into reactive surface sites occurs with an efficiency independent from the local photon flux density.

In general, it is assumed that in heterogeneous photocatalytic reactions, the reacting substrate is adsorbed on the surface of the photocatalyst (Equation (4)). Thus, a photocatalyst particle provides both the sites for the formation of the reactive surface sites and the sites at which the reactant adsorbs. With the amounts of surface sites available to yield the reactive surface sites and to adsorb the reactant per unit mass of photocatalyst, $f_{\mathrm{rs}}$ and $f_{\mathrm{a}}$, and the coverage of the photocatalyst by the reactant, $\theta$, the product $C_{\mathrm{rs}, 0} C_{\mathrm{R}}$ can be written as $\gamma f_{\mathrm{rs}} f_{\mathrm{a}} \theta$. With the rate constant $k_{\mathrm{r}}=k f_{\mathrm{rs}} f_{\mathrm{a}}$ and the Langmuir adsorption isotherm $\theta=K_{\mathrm{a}} C /\left(1+K_{\mathrm{a}} C\right)$, the rate law

$$
\frac{\mathrm{d} C}{\mathrm{~d} t}=\frac{k_{\mathrm{r}} K_{\mathrm{a}} C}{\epsilon d\left(1+K_{\mathrm{a}} C\right)} \times \ln \left(\frac{\epsilon \gamma \eta I_{0}\left(1+K_{\mathrm{a}} C\right)}{k_{\mathrm{d}}\left(1+K_{\mathrm{a}} C\right)+\gamma k_{\mathrm{r}} K_{\mathrm{a}} C}+1\right)
$$

is obtained [63]. This rate law (that by the way can be written like Equation (12)) enables to correlate experimentally accessible reaction rates with the concentration of the reactant $C$, the mass concentration of the heterogeneous photocatalyst $\gamma$, and the photon flux density $I_{0}$.

The rate law given by Equation (19) was employed here to analyze the kinetic data presented in the Figures 1B, 2B, and 4B (Figure 6). The use of this equation seems reasonable when the light source 
is considered as a sphere in the center of the black body photoreactor. Furthermore, it is assumed that reflection at the interface between the sphere and the suspension as well as back-scattering finally causes the photons incident into the sphere to penetrate uniformly over the entire surface into the suspension. The volume in which the photocatalytic reaction occurs is hence a thin, uniformly irradiated layer surrounding the outer wall of this sphere. Neglecting the change in photon flux density due to the light propagation geometry, the local volumetric rate of photon absorption is thus given by Equation (15) and $I_{0}=\frac{1}{4 \pi r_{\text {sphere }}^{2}}\left(\frac{\mathrm{d} n_{\mathrm{p}}}{\mathrm{d} t}\right)$. It is a characteristic of a black body photoreactor in which all entering photons are absorbed inside the suspension, that the external geometry of the reactor does not affect the reaction rate. It is thus appropriate to consider the entire suspension volume $V$ as a layer of thickness $d$ spherically enveloping the central light-emitting sphere.

The experimental results presented above clearly evince that DCA adsorbs at the surface of Hombikat UV 100 under the experimental conditions employed in this study. From the values of $\gamma, C_{\mathrm{s}}$ and $C_{0}$ given in Figures 1A, 2A, 3A, and 4A, an average amount of adsorbed DCA per unit mass of the photocatalyst, $\left(C_{\mathrm{s}}-C_{0}\right) / \gamma$, was calculated to be $151 \pm 42 \mu \mathrm{mol} \mathrm{g}^{-1}$. The large variance of this value is an additional indication of the assumed inhomogeneity of the photocatalyst Hombikat UV 100. Hufschmidt et al. reported DCA loadings of $45-60 \mu \mathrm{mol} \mathrm{g}^{-1}$ and $70-90 \mu \mathrm{mol} \mathrm{g}^{-1}$ for platinized anatase-rutile composites (Degussa P25, $50 \mathrm{~m}^{2} \mathrm{~g}^{-1}$ ) and platinized anatase (Hombikat UV $100,300 \mathrm{~m}^{2} \mathrm{~g}^{-1}$ ), respectively, in aqueous suspensions at $\mathrm{pH} 3$ [65]. From data published by Czili and Horváth for the adsorption of DCA at $\mathrm{pH} 3$, values of $\approx 50 \mu \mathrm{mol} \mathrm{g}^{-1}, \approx 20 \mu \mathrm{mol} \mathrm{g}-1$, and $\approx 20 \mu \mathrm{mol} \mathrm{g}^{-1}$ are estimated for the anatase-rutile composite Degussa P25 $\left(50 \mathrm{~m}^{2} \mathrm{~g}^{-1}\right)$, anatase $\left(9.6 \mathrm{~m}^{2} \mathrm{~g}^{-1}\right)$, and rutile $\left(9.7 \mathrm{~m}^{2} \mathrm{~g}^{-1}\right)$, respectively [49]. The calculated DCA loading on Hombikat UV 100 thus agrees reasonably well with published values. Several authors have described the adsorption of aliphatic carboxylic acids, such as acetic acid and dichloroacetic acid, from acidic aqueous solutions on $\mathrm{TiO}_{2}$ surfaces by Langmuir adsorption isotherms [44,66,67]. Krivec et al. investigated the adsorption of DCA on Degussa P25 at pH 3 and calculated the maximum amount of adsorbed DCA to be $43 \mu \mathrm{mol} \mathrm{g}^{-1}$. The maximum amount was found to decrease to $22 \mu \mathrm{mol} \mathrm{g}{ }^{-1}$ in the presence of $0.5 \mathrm{mmol} \mathrm{L}^{-1} \mathrm{Cl}^{-}$. They reported a Langmuir adsorption constant for DCA of $1.64 \mathrm{~L} \mathrm{mmol}^{-1}$ unaffected by the presence of $\mathrm{Cl}^{-}$[44]. It thus seems justified to analyze the experimental data obtained here employing the rate law Equation (19), which requires Langmuir adsorption of the DCA on the Hombikat UV 100 surface.

The reaction rates calculated with Equation (19) are presented in Figure 6. The experimentally obtained reaction rates are included in this figure for the purpose of comparison. The kinetic parameters necessary for the calculation (given in the caption of Figure 6) were calculated by nonlinear fitting to the experimental data using a genetic algorithm [68]. However, it must be emphasized that the number of experimental data is too low to determine the parameters used in the computation with high accuracy. Despite this uncertainty resulting from the limited number of available data points (and from the simplifying assumptions made in the derivation of the rate law), a reasonable good agreement between the calculated and the experimentally obtained reaction rates becomes evident (Figure 6).

A Langmuir-Hinshelwood-like dependence of the reaction rate on the DCA concentration becomes obvious from Figure 6A. With the adsorption constant $K_{\mathrm{a}}=1.023 \mathrm{~L} \mathrm{mmol}^{-1}$ used for the computation of the lines in Figure 6, surface coverages varying from $\theta=0.67$ to $\theta=0.95$ are calculated for suspensions containing between $2 \mathrm{mmol} \mathrm{L}^{-1}$ and $20 \mathrm{mmol} \mathrm{L}^{-1} \mathrm{DCA}$. These coverages agree reasonable well with $0.79 \leq \theta \leq 0.97$ which are calculated with the experimentally obtained adsorption constant $\left(K_{\mathrm{a}}=1.866\right.$ $\pm 1.464 \mathrm{~L} \mathrm{mmol}^{-1}$ ) for this range of DCA concentrations. The computational results show, in agreement with the experimental data, the independence of the reaction rate from the mass concentration of the photocatalyst in the range examined here (Figure 6B). Even for the dependence of the reaction rate on the photon flux, a sufficiently good agreement between the experimentally determined rates and the values calculated with Equation (19) is obtained (Figure 6C). 

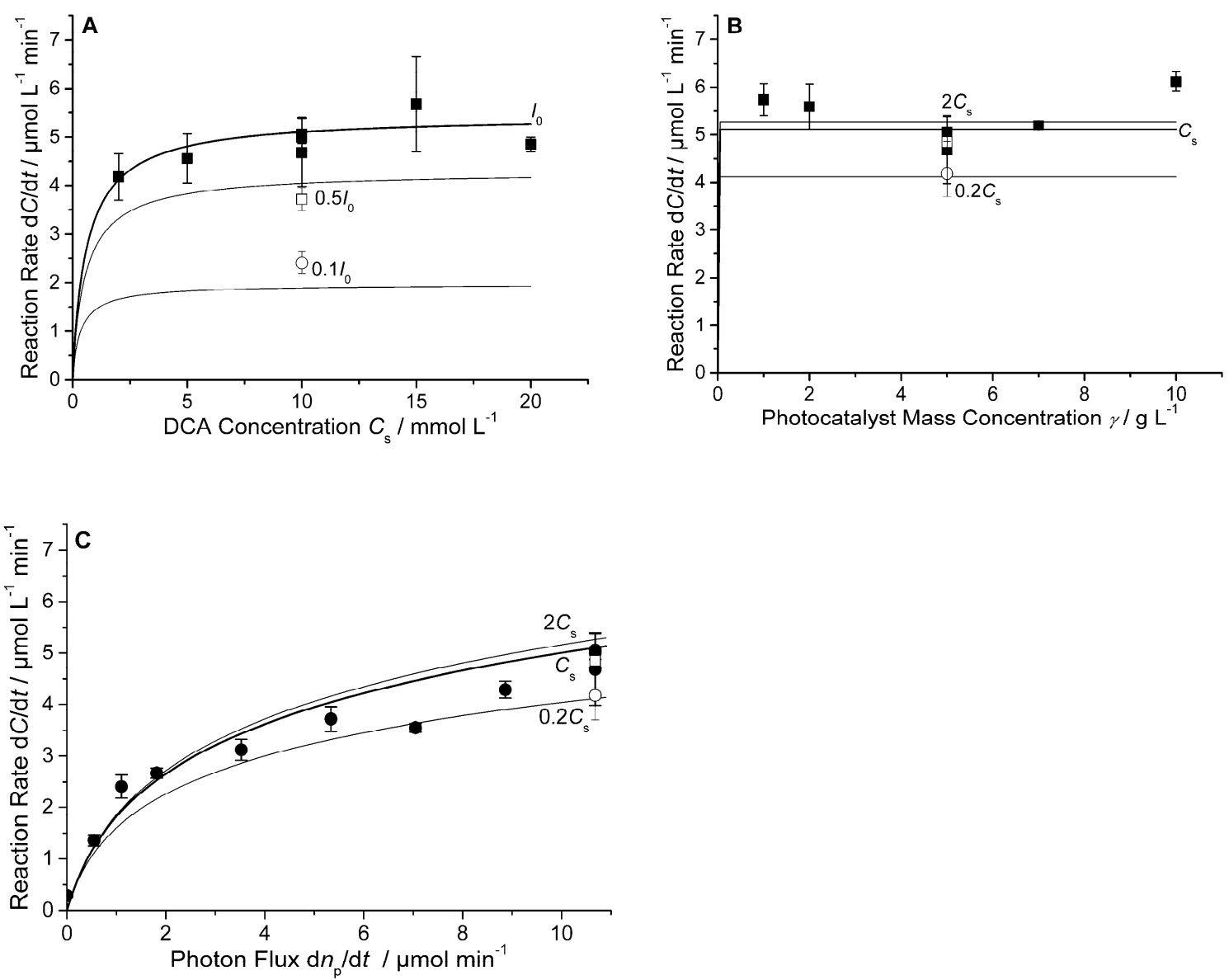

Figure 6. Comparison between calculated and experimental reaction rates. Reaction rates $\mathrm{d} C(\mathrm{DCA}) / \mathrm{d} t$ vs. (A) the DCA concentration $C_{\mathrm{s}}$ at three photon flux densities $\left(I_{0}=(1 / \mathrm{A})\left(\mathrm{d} n_{\mathrm{p}} / \mathrm{d} t\right)\right.$ with $\mathrm{A}=3.8 \mathrm{~cm}^{2}$ and $\mathrm{d} n_{\mathrm{p}} / \mathrm{d} t=10.7 \mu \mathrm{mol} \mathrm{\textrm {min } ^ { - 1 } )}$; (B) the mass concentration of the photocatalyst; and $(\mathbf{C})$ the photon flux $\mathrm{d} n_{\mathrm{p}} / \mathrm{d} t$ at different DCA concentrations $\left(C_{\mathrm{s}}=10 \mu \mathrm{mol} \mathrm{L}^{-1}\right)$. The symbols represent experimental data points. The lines were calculated employing Equation (19) with $k_{\mathrm{r}}=58.78 \mu \mathrm{mol} \mathrm{g}^{-1} \mathrm{~min}^{-1}$, $K_{\mathrm{a}}=1.023 \mathrm{~L} \mathrm{mmol}^{-1}, \varepsilon=8.169 \mathrm{~L} \mathrm{~cm}^{-1} \mathrm{~g}^{-1}, \eta=51.25 \times 10^{-3}$, and $k_{\mathrm{d}}=3.73 \times 10-^{11} \mu \mathrm{mol} \mathrm{L}^{-1} \mathrm{~min}^{-1}$.

Naturally, the kinetic model enables some predictions as long as other physico-chemical parameters known to affect the reaction rate (e.g., temperature, $\mathrm{pH}, \mathrm{pO}_{2}$ ) are kept constant: (i) The Langmuir-Hinshelwood-like dependence of the photocatalytic DCA degradation rate in the presence of Hombikat UV 100 on the substrate concentration is not affected by changing the photon flux. However, a decrease of the photon flux results in a significant decrease of the reaction rates (Figure 6A). (ii) A change of the mass concentration does not affect the reaction rate when the substrate concentration as well as the photon flux is fixed (Figure 6B). (iii) The impact of the photon flux on the reaction rate is low at high substrate concentrations, where the surface is almost saturated by adsorbed substrate (Figure 6C). (iv) Changing the mass concentration of the photocatalyst over a wide range has almost no impact on the reaction rate as long as the photon flux is kept constant. (v) No impact of the mass concentration on the photon flux dependence of the reaction rate is observed in the range $1 \mathrm{~g} \mathrm{~L}^{-1} \leq \gamma \leq 10 \mathrm{~g} \mathrm{~L}^{-1}$ when the substrate concentration is fixed. The rate law chosen here to analyze the experimental data thus predicts reaction conditions in which the reaction rates at constant light intensity are almost independent from both the substrate concentration and the mass concentration of the photocatalyst over wide ranges of these concentrations. Under these reaction conditions, it does not appear to be inappropriate to refer to the kinetics as a zero-order kinetics with regard to both the substrate concentration and the mass concentration of the photocatalyst. 


\section{Materials and Methods}

Dichloroacetic acid (DCA) was purchased from Sigma-Aldrich, while potassium hydroxide and potassium nitrate were purchased from Fluka and Merck respectively. All mentioned chemicals were of analytical grade and used without further purification. Hombikat UV 100 (Sachtleben Chemie, now Venator Germany GmbH, Duisburg, Germany), an anatase $\mathrm{TiO}_{2}$ with a BET surface area of $280 \mathrm{~m}^{2} \mathrm{~g}^{-1}$ was used as the photocatalysts. Ultrapure water $(\geq 18.2 \mathrm{M} \Omega \mathrm{cm})$ was applied in all experimental runs.

Stock solutions were prepared by dissolving potassium nitrate and DCA in water resulting in solutions with $10 \mathrm{mmol} \mathrm{L}^{-1}$ potassium nitrate and varying DCA concentrations $\left(2 \mathrm{mmol} \mathrm{L}^{-1}\right.$ to $20 \mathrm{mmol} \mathrm{L}^{-1}$ ). The salt was added to minimize the change of the ionic strength associated with the release of $\mathrm{Cl}^{-}$during the photocatalytic degradation of DCA. The required amounts of $\mathrm{TiO}_{2}$ were added to these solutions to result in mass concentrations of the photocatalyst varying between $1 \mathrm{~g} \mathrm{~L}^{-1}$ and $10 \mathrm{~g} \mathrm{~L}^{-1}$. The $\mathrm{pH}$ values of the freshly prepared suspensions, which depend on the DCA concentration, were lower than 2.8. They were adjusted at $\mathrm{pH} 3$ by addition of potassium hydroxide to ensure the comparability between the results of the experimental runs.

The photocatalytic runs were performed in glass bottles of suitable size containing different suspension volumes $(80 \mathrm{~mL}, 100 \mathrm{~mL}, 250 \mathrm{~mL}, 400 \mathrm{~mL}, 600 \mathrm{~mL}$, and $900 \mathrm{~mL})$ with a monochromatic light source (Omicron Laserage Laserprodukte $\mathrm{GmbH}$, Rodgau-Dudenhofen, Germany, $\lambda_{\max }=365 \mathrm{~nm}$ with full width at half maximum $=10 \mathrm{~nm}$ as determined with a B\&W Tek SpectraRadS Xpress (B\&W Tek, Newark, DE, USA), photon flux $\mathrm{d} n_{\mathrm{p}, \mathrm{em}} / \mathrm{d} t=10.7 \mu \mathrm{mol} \mathrm{min}^{-1}$ (i.e., $0.057 \mathrm{~mol}$ photons $\mathrm{m}^{-2} \mathrm{~s}^{-1}$ at the outlet of the waveguide) as determined by ferrioxalate actinometry [69]) equipped with a suitable waveguide ( $2 \mathrm{~mm}$ core diameter) within a glass tube (outer diameter $=11 \mathrm{~mm}$, inner diameter $=9 \mathrm{~mm}$ ). The outlet of the waveguide was placed in the center of the suspension to ensure that the light entrance is surrounded by the suspension in all three spatial directions.

In all experimental runs, the suspension was magnetically stirred for $2 \mathrm{~h}$ in the dark in order to establish the adsorption equilibrium. Subsequently, the light source was switched on and the stirred suspension was irradiated for $3 \mathrm{~h}$. Samples were taken every $30 \mathrm{~min}$ and centrifuged for $5 \mathrm{~min}$ at $13,000 \mathrm{rpm}$. The supernatant solutions were filtered through syringe filters with $0.2 \mathrm{~mm}$ pore size and then diluted 1:20. Quantitative analysis of DCA and chloride was performed by high performance ion chromatography (HPIC) employing a Dionex ICS-1000 instrument (Thermo Fisher Scientific, Waltham, MA, USA) equipped with an anion exchange column (Dionex Ion Pac AS9-HC 2V $250 \mathrm{~mm}$ ) in combination with a guard column (Dionex Ion Pac AG9-HC 2V $50 \mathrm{~mm}$, Thermo Fisher Scientific, Waltham, MA, USA). The column temperature was set to $35^{\circ} \mathrm{C}$. The mobile phase (flow rate $=0.3 \mathrm{~mL} \mathrm{~min}^{-1}$ ) consisted of an aqueous solution of $\mathrm{Na}_{2} \mathrm{CO}_{3}\left(8 \mathrm{mmol} \mathrm{L}^{-1}\right)$ and $\mathrm{NaHCO}_{3}$ $\left(1.5 \mathrm{mmol} \mathrm{L}^{-1}\right)$.

\section{Conclusions}

The experimental results presented above clearly evince that the rate of a photocatalytic reaction in suspension can be determined unaffected by the scattering properties of the photocatalyst when a black body photoreactor is employed. It was shown that experimental conditions can be achieved under which the rate of the photocatalytic degradation reaction, defined as the time derivative of the extent of reaction, is constant within the limits of experimental error. Employing a black body photoreactor, rates of conversion, and quantum yields can thus be determined with sufficiently good reproducibility.

At the risk of spreading platitudes, a few remarks on the comparative assessment of different photocatalysts will be given:

(i) For comparative measurements in suspensions, it should be ensured that the photocatalyst is the only light-absorbing species. The probe compound as well as intermediates and products formed during the photocatalytic reaction must therefore be optically transparent at the wavelength used for the excitation of the photocatalyst. 
(ii) The experimental conditions should allow the determination of the amount of photons absorbed by the photocatalyst.

(iii) Comparative activity measurements with a set of photocatalysts should be performed at high concentrations of the probe compound. This ensures that observed differences in rates of conversion or quantum yields are not due to significant differences in the coverage of the photocatalyst surface with the probe compound.

(iv) As the measure of the activity of a solid photocatalyst, it is advisable to indicate the quantum yield or the rate of conversion of the probe compound obtained under the conditions of zero-order kinetics. This enables the direct comparison of reported data without any necessary conversions of volume, mass, or area related reaction rates.

(v) It seems doubtful that rates of conversion that differ by less than $10 \%$ indicate differences in photocatalytic activities. If necessary, a sufficiently high number of replicate measurements are to be performed demonstrating that differences between the determined activities of photocatalysts of less than $10 \%$ are statistically significant.

Author Contributions: Conceptualization, R.D. and D.W.B.; Formal analysis, L.M. and R.D.; Funding acquisition, D.W.B.; Investigation, L.M.; Supervision, R.D. and D.W.B.; Visualization, L.M. and R.D.; Writing一original draft, L.M.; Writing-review \& editing, L.M. and R.D.

Funding: Financial support from the Global Research Laboratory program (2014 K1 A1 A2041044), Korea government (MSIP) through NRF is gratefully acknowledged.

Acknowledgments: L.M. gratefully acknowledges a scholarship of the Deutscher Akademischer Austauschdienst (DAAD). The unknown reviewers are thanked for their valuable comments. R.D. thanks Jonathan Z. Bloh (DECHEMA-Forschungsinstitut, Frankfurt, Germany) for a stimulating discussion. The publication of this article was funded by the Open Access Fund of the Gottfried Wilhelm Leibniz Universität Hannover.

Conflicts of Interest: The authors declare no conflict of interest.

\section{References}

1. Ge, J.; Zhang, Y.; Heo, Y.-J.; Park, S.-J. Advanced design and synthesis of composite photocatalysts for the remediation of wastewater: A review. Catalysts 2019, 9, 122. [CrossRef]

2. Kampouri, S.; Stylianou, K.C. Dual-functional photocatalysis for simultaneous hydrogen production and oxidation of organic substances. ACS Catal. 2019, 9, 4247-4270. [CrossRef]

3. Kanan, S.; Moyet, M.A.; Arthur, R.B.; Patterson, H.H. Recent advances on $\mathrm{TiO}_{2}$-based photocatalysts toward the degradation of pesticides and major organic pollutants from water bodies. Catal. Rev. 2019, 43, 1-65. [CrossRef]

4. Takanabe, K. Photocatalytic water splitting: Quantitative approaches toward photocatalyst by design. ACS Catal. 2017, 7, 8006-8022. [CrossRef]

5. Christoforidis, K.C.; Fornasiero, P. Photocatalysis for hydrogen production and $\mathrm{CO}_{2}$ reduction: The case of copper-catalysts. Chem CatChem 2019, 11, 368-382. [CrossRef]

6. Hisatomi, T.; Domen, K. Reaction systems for solar hydrogen production via water splitting with particulate semiconductor photocatalysts. Nat. Catal. 2019, 2, 387. [CrossRef]

7. Kang, X.; Liu, S.; Dai, Z.; He, Y.; Song, X.; Tan, Z. Titanium dioxide: From engineering to applications. Catalysts 2019, 9, 191. [CrossRef]

8. Wang, Z.; Li, C.; Domen, K. Recent developments in heterogeneous photocatalysts for solar-driven overall water splitting. Chem. Soc. Rev. 2019, 48, 2109-2125. [CrossRef]

9. Kisch, H.; Bahnemann, D. Best practice in photocatalysis: Comparing rates or apparent quantum yields? J. Phys. Chem. Lett. 2015, 6, 1907-1910. [CrossRef]

10. Qureshi, M.; Takanabe, K. Insights on measuring and reporting heterogeneous photocatalysis: Efficiency definitions and setup examples. Chem. Mater. 2017, 29, 158-167. [CrossRef]

11. Hoque, M.A.; Guzman, M.I. Photocatalytic activity: Experimental features to report in heterogeneous photocatalysis. Materials 2018, 11, 1990. [CrossRef] [PubMed] 
12. Schiavello, M.; Augugliaro, V.; Palmisano, L. An experimental method for the determination of the photon flow reflected and absorbed by aqueous dispersions containing polycrystalline solids in heterogeneous photocatalysis. J. Catal. 1991, 127, 332-341. [CrossRef]

13. Brandi, R.J.; Alfano, O.M.; Cassano, A.E. Evaluation of radiation absorption in slurry photocatalytic reactors. 1. Assessment of methods in use and new proposal. Environ. Sci. Technol. 2000, 34, 2623-2630. [CrossRef]

14. Brandi, R.J.; Citroni, M.A.; Alfano, O.M.; Cassano, A.E. Absolute quantum yields in photocatalytic slurry reactors. Chem. Eng. Sci. 2003, 58, 979-985. [CrossRef]

15. Satuf, M.L.; Brandi, R.J.; Cassano, A.E.; Alfano, O.M. Experimental method to evaluate the optical properties of aqueous titanium dioxide suspensions. Ind. Eng. Chem. Res. 2005, 44, 6643-6649. [CrossRef]

16. Cabrera, M.I.; Alfano, O.M.; Cassano, A.E. Absorption and scattering coefficients of titanium dioxide particulate suspensions in water. J. Phys. Chem. 1996, 100, 20043-20050. [CrossRef]

17. Loddo, V.; Addamo, M.; Augugliaro, V.; Palmisano, L.; Schiavello, M.; Garrone, E. Optical properties and quantum yield determination in photocatalytic suspensions. AICHE J. 2006, 52, 2565-2574. [CrossRef]

18. Yurdakal, S.; Loddo, V.; Bayarri Ferrer, B.; Palmisano, G.; Augugliaro, V.; Giménez Farreras, J.; Palmisano, L. Optical properties of $\mathrm{TiO}_{2}$ suspensions: Influence of $\mathrm{pH}$ and powder concentration on mean particle size. Ind. Eng. Chem. Res. 2007, 46, 7620-7626. [CrossRef]

19. Emeline, A.V.; Zhang, X.; Jin, M.; Murakami, T.; Fujishima, A. Application of a "black body" like reactor for measurements of quantum yields of photochemical reactions in heterogeneous systems. J. Phys. Chem. B 2006, 110, 7409-7413. [CrossRef]

20. De los Milagros Ballari, M.; Alfano, O.O.; Cassano, A.E. Photocatalytic degradation of dichloroacetic acid. A kinetic study with a mechanistically based reaction model. Ind. Eng. Chem. Res. 2009, 48, 1847-1858. [CrossRef]

21. Zalazar, C.S.; Romero, R.L.; Martín, C.A.; Cassano, A.E. Photocatalytic intrinsic reaction kinetics. I: Mineralization of dichloroacetic acid. Chem. Eng. Sci. 2005, 60, 5240-5254. [CrossRef]

22. Zalazar, C.S.; Martin, C.A.; Cassano, A.E. Photocatalytic intrinsic reaction kinetics. II: Effects of oxygen concentration on the kinetics of the photocatalytic degradation of dichloroacetic acid. Chem. Eng. Sci. 2006, 60, 4311-4322. [CrossRef]

23. Megatif, L.; Dillert, R.; Bahnemann, D.W. A method to compare the activities of semiconductor photocatalysts in liquid-Solid systems. ChemPhotoChem 2018, 2, 948-951. [CrossRef]

24. Megatif, L.; Dillert, R.; Bahnemann, D.W. Determination of the quantum yield of a heterogeneous photocatalytic reaction employing a black body photoreactor. Catal. Today 2019, in press. [CrossRef]

25. Sakthivel, S.; Hidalgo, M.C.; Bahnemann, D.W.; Geissen, S.-U.; Murugesan, V.; Vogelpohl, A. A fine route to tune the photocatalytic activity of $\mathrm{TiO}_{2}$. Appl. Catal. B Environ. 2006, 63, 31-40. [CrossRef]

26. Chemseddine, A.; Boehm, H.P. A study of the primary step in the photochemical degradation of acetic acid and chloroacetic acids on a $\mathrm{TiO}_{2}$ photocatalyst. J. Mol. Catal. 1990, 60, 295-311. [CrossRef]

27. Bahnemann, D.W.; Kholuiskaya, S.N.; Dillert, R.; Kulak, A.I.; Kokorin, A.I. Photodestruction of dichloroacetic acid catalyzed by nano-sized $\mathrm{TiO}_{2}$ particles. Appl. Catal. B Environ. 2002, 36, 161-169. [CrossRef]

28. Lindner, M.; Bahnemann, D.W.; Hirthe, B.; Griebler, W.-D. Solar water detoxification: $\mathrm{Novel} \mathrm{TiO}_{2}$ powders as highly active photocatalysts. J. Sol. Energy Eng. 1997, 119, 120-125. [CrossRef]

29. Lindner, M.; Theurich, J.; Bahnemann, D. Photocatalytic degradation of organic compounds: Accelerating the process efficiency. Water Sci. Technol. 1997, 35, 79-86. [CrossRef]

30. Lindner, M. Optimierung der Photokatalytischen Wasserreinigung mit Titandioxid: Festkörper-und Oberflächenstruktur des Photokatalysators. Ph.D. Thesis, Universität Hannover, Hannover, Germany, 1997.

31. Laidler, K.J. A glossary of terms used in chemical kinetics, including reaction dynamics (IUPAC Recommendations 1996). Pure Appl. Chem. 1996, 68, 149-192. [CrossRef]

32. Szakács, Z.; Hägele, G. Accurate determination of low pK values by ${ }^{1} \mathrm{H}$ NMR titration. Talanta 2004, 62, 819-825. [CrossRef]

33. Kraeutler, B.; Bard, A.J. Heterogeneous photocatalytic synthesis of methane from acetic acid-New Kolbe reaction pathway. J. Am. Chem. Soc. 1978, 100, 2239-2240. [CrossRef]

34. Kraeutler, B.; Bard, A.J. Heterogeneous photocatalytic decomposition of saturated carboxylic acids on titanium dioxide powder. Decarboxylative route to alkanes. J. Am. Chem. Soc. 1978, 100, 5985-5992. [CrossRef] 
35. Kraeutler, B.; Jaeger, C.D.; Bard, A.J. Direct observation of radical intermediates in the photo-Kolbe reaction-Heterogeneous photocatalytic radical formation by electron spin resonance. J. Am. Chem. Soc. 1978, 100, 4903-4905. [CrossRef]

36. Kaise, M.; Kondoh, H.; Nishihara, C.; Nozoye, H.; Shindo, H.; Nimura, S.; Kikuchi, O. Photocatalytic reactions of acetic acid on platinum-loaded $\mathrm{TiO}_{2}$ : ESR evidence of radical intermediates in the photo-Kolbe reaction. J. Chem. Soc. Chem. Commun. 1993, 395-396. [CrossRef]

37. Kaise, M.; Nagai, H.; Tokuhashi, K.; Kondo, S.; Nimura, S.; Kikuchi, O. Electron spin resonance studies of photocatalytic interface reactions of suspended $\mathrm{M} / \mathrm{TiO}_{2}(\mathrm{M}=\mathrm{Pt}, \mathrm{Pd}, \mathrm{Ir}, \mathrm{Rh}, \mathrm{Os}$, or $\mathrm{Ru})$ with alcohol and acetic acid in aqueous media. Langmuir 1994, 10, 1345-1347. [CrossRef]

38. Nosaka, Y.; Koenuma, K.; Ushida, K.; Kira, A. Reaction mechanism of the decomposition of acetic acid on illuminated $\mathrm{TiO}_{2}$ powder studied by means of in situ electron spin resonance measurements. Langmuir 1996, 12, 736-738. [CrossRef]

39. Nosaka, Y.; Kishimoto, M.; Nishino, J. Factors governing the initial process of $\mathrm{TiO}_{2}$ photocatalysis studied by means of in-situ electron spin resonance measurements. J. Phys. Chem. B 1998, 102, 10279-10283. [CrossRef]

40. Wolff, K.; Bockelmann, D.; Bahnemann, D.W. Mechanistic aspects of chemical transformations in photocatalytic systems. In Symposium on Electronic and Ionic Properties of Silver Halides. Common Trends with Photocatalysis (Proc. ISET 44th Annual Conference); Levy, B., Ed.; IS\&T: Springfield, VA, USA, 1991; pp. 259-267.

41. Wolff, K. Mechanistische Untersuchungen zum Oxidationsprozess an der Belichteten Titandioxid/Wasser-Grenzfläche. Ph.D. Thesis, Universität Hannover, Hannover, Germany, 1993.

42. Hamid, S.; Ivanova, I.; Jeon, T.H.; Dillert, R.; Choi, W.; Bahnemann, D.W. Photocatalytic conversion of acetate into molecular hydrogen and hydrocarbons over $\mathrm{Pt} / \mathrm{TiO}_{2}: \mathrm{pH}$ dependent formation of Kolbe and Hofer-Moest products. J. Catal. 2017, 349, 128-135. [CrossRef]

43. Hamid, S.; Dillert, R.; Bahnemann, D.W. Photocatalytic reforming of aqueous acetic acid into molecular hydrogen and hydrocarbons over co-catalyst-loaded $\mathrm{TiO}_{2}$ : Shifting the product distribution. J. Phys. Chem. C 2018, 122, 12792-12809. [CrossRef]

44. Krivec, M.; Dillert, R.; Bahnemann, D.W.; Mehle, A.; Štrancar, J.; Dražić, G. The nature of chlorine-inhibition of photocatalytic degradation of dichloroacetic acid in a $\mathrm{TiO}_{2}$-based microreactor. Phys. Chem. Chem. Phys. 2014, 16, 14867-14873. [CrossRef]

45. Doyle, K.J.; Tran, H.; Baldoni-Olivencia, M.; Karabulut, M.; Hoggard, P.E. Photocatalytic degradation of dichloromethane by chlorocuprate (II) ions. Inorg. Chem. 2008, 47, 7029-7034. [CrossRef]

46. Calza, P.; Minero, C.; Pelizzetti, E. Photocatalytically assisted hydrolysis of chlorinated methanes under anaerobic conditions. Environ. Sci. Technol. 1997, 31, 2198-2203. [CrossRef]

47. Mozia, S.; Heciak, A.; Morawski, A.W. The influence of physico-chemical properties of $\mathrm{TiO}_{2}$ on photocatalytic generation of $C_{1}-C_{3}$ hydrocarbons and hydrogen from aqueous solution of acetic acid. Appl. Catal. B Environ. 2011, 104, 21-29. [CrossRef]

48. Mozia, S.; Kulagowska, A.; Morawski, A.W. Formation of combustible hydrocarbons and $\mathrm{H}_{2}$ during photocatalytic decomposition of various organic compounds under aerated and deaerated conditions. Molecules 2014, 19, 19633-19647. [CrossRef]

49. Czili, H.; Horváth, A. Photodegradation of chloroacetic acids over bare and silver-deposited $\mathrm{TiO}_{2}$ : Identification of species attacking model compounds, a mechanistic approach. Appl. Catal. B Environ. 2009, 89, 342-348. [CrossRef]

50. Mao, Y.; Schoeneich, C.; Asmus, K.D. Identification of organic acids and other intermediates in oxidative degradation of chlorinated ethanes on Titania surfaces en route to mineralization: a combined photocatalytic and radiation chemical study. J. Phys. Chem. 1991, 95, 10080-10089. [CrossRef]

51. Ohtani, B.; Prieto-Mahaney, O.O.; Li, D.; Abe, R. What is Degussa (Evonik) P25? Crystalline composition analysis, reconstruction from isolated pure particles and photocatalytic activity test. J. Photochem. Photobiol. A Chem. 2010, 216, 179-182. [CrossRef]

52. Kisch, H. Semiconductor Photocatalysis. Principles and Applications; Wiley-VCH Verlag GmbH \& Co. KGaA: Weinheim, Germany, 2015; p. 93.

53. Mills, A.; O'Rourke, C.; Moore, K. Powder semiconductor photocatalysis in aqueous solution: An overview of kinetics-based reaction mechanisms. J. Photochem. Photobiol. A Chem. 2015, 310, 66-105. [CrossRef] 
54. Turchi, C.; Ollis, D.F. Photocatalytic degradation of organic water contaminants: Mechanisms involving hydroxyl radical attack. J. Catal. 1990, 122, 178-192. [CrossRef]

55. Ollis, D.F. Kinetic disguises in heterogeneous photocatalysis. Top. Catal. 2005, 35, 217-223. [CrossRef]

56. Ollis, D.F. Kinetics of liquid phase photocatalyzed reactions: An illuminating approach. J. Phys. Chem. B 2005, 109, 2439-2444. [CrossRef]

57. Ollis, D.F. Kinetics of photocatalyzed reactions: Five lessons learned. Front. Chem. 2018, 6, 378. [CrossRef]

58. Mills, A.; Wang, J.; Ollis, D.F. Kinetics of liquid phase semiconductor photoassisted reactions: Supporting observations for a pseudo-steady-state model. J. Phys. Chem. B 2006, 110, 14386-14390. [CrossRef]

59. Emeline, A.V.; Ryabchuk, V.K.; Serpone, N. Dogmas and misconceptions in heterogeneous photocatalysis. Some enlightened reflections. J. Phys. Chem. B 2005, 109, 18515-18521. [CrossRef]

60. Minero, C.; Vione, D. A quantitative evalution of the photocatalytic performance of $\mathrm{TiO}_{2}$ slurries. Appl. Catal. B Environ. 2006, 67, 257-269. [CrossRef]

61. Minero, C.; Maurino, V.; Vione, D. Photocatalytic mechanisms and reaction pathways drawn from kinetic and probe molecules. In Photocatalysis and Water Purification; Pichat, P., Ed.; Wiley-VCH: Weinheim, Germany, 2013; pp. 53-72.

62. Burek, B.O.; Bahnemann, D.W.; Bloh, J.Z. Modeling and optimization of the photocatalytic reduction of molecular oxygen to hydrogen peroxide over titanium dioxide. ACS Catal. 2019, 9, 25-37. [CrossRef]

63. Bloh, J.Z. A holistic approach to model the kinetics of photocatalytic reactions. Front. Chem. 2019, 7, 128. [CrossRef]

64. Emeline, A.V.; Ryabchuk, V.; Serpone, N. Factors affecting the efficiency of a photocatalyzed process in aqueous metal-oxide dispersions. J. Photochem. Photobiol. A Chem. 2000, 133, 89-97. [CrossRef]

65. Hufschmidt, D.; Bahnemann, D.; Testa, J.J.; Emilio, C.A.; Litter, M.I. Enhancement of the photocatalytic activity of various $\mathrm{TiO}_{2}$ materials by platinisation. J. Photochem. Photobiol. A Chem. 2002, 148, 223-231. [CrossRef]

66. Flaig-Baumann, R.; Herrmann, M.; Boehm, H.P. Über die Chemie der Oberfläche des Titandioxids. III. Reaktionen der basischen Hydroxylgruppen auf der Oberfläche. Z. Anorg. Allg. Chem. 1970, 372, $296-307$. [CrossRef]

67. Boehm, H.P. Acidic and basic properties of hydroxylated metal oxide surfaces. Discuss. Faraday Soc. 1971, 52, 264-275. [CrossRef]

68. Dillert, R.; Engel, A.; Große, J.; Lindner, P.; Bahnemann, D.W. Light intensity dependence of the kinetics of the photocatalytic oxidation of nitrogen(II) oxide at the surface of $\mathrm{TiO}_{2}$. Phys. Chem. Chem. Phys. 2013, 15, 20876-20886. [CrossRef]

69. Hatchard, C.G.; Parker, C.A.; Bowen, E.J. A new sensitive chemical actinometer-II. Potassium ferrioxalate as a standard chemical actinometer. Proc. R. Soc. Lond. A 1956, 235, 518-536. [CrossRef] 